\title{
Women's Uptake of Medicare Benefits Schedule Mental Health Items for General Practitioners, Psychologists and Other Allied Mental Health Professionals
}

\begin{abstract}
Objective: To describe uptake of Medicare Benefits Schedule mental health (MH) items by women in the Australian Longitudinal Study on Women's Health (ALSWH); compare characteristics of women by $\mathrm{MH}$ service use, and investigate the impact on Medicare costs.

Design, setting and participants: Analysis of linked survey data and Medicare records (November 2006 - December 2007) for 14911 consenting women across three birth cohorts. Self report and Medicare data defined four mutually exclusive groups: women with $\mathrm{MH}$ claims; women without $\mathrm{MH}$ claims who reported a mental health condition on their most recent survey (2005, 2006, or 2007 depending on cohort); women without MH claims who reported a mental health condition on a past survey (since 1996), and women without $\mathrm{MH}$ claims who did not report a mental health condition on any survey. Chi squared tests, ttests and Generalised Mixture Models were used to describe between group differences, longitudinal patterns in service use and costs, and trends in mental health scores.
\end{abstract}

Main outcome measures: Mental Health Index scores (SF-36) from ALSWH surveys, patient (out of pocket) and benefit (government) costs from Medicare data.

Results: A large proportion of women who reported mental health problems made no $\mathrm{MH}$ claims. Socioeconomically disadvantaged women were less likely to use the services regardless of mental health needs. $\mathrm{MH}$ items are associated with higher costs to women and government. Conclusion: While there has been rapid uptake of $\mathrm{MH}$ items, uptake by women with mental health needs is low and there is potential socioeconomic inequity.

\section{Word count:}

Abstract: 247

Text: 2,376 


\section{INTRODUCTION}

Depression is a common problem and is particularly prevalent among women. [1, 2] Women with depression may benefit from psychotherapeutic counselling (in addition to or instead of anti-depressant medication) [3], however this form of treatment has been unaffordable for many [4].

Mental health problems differentially affect women with greater socio-economic stress who may be least likely to access mental health services under a user-pays scheme [5]. To improve access to mental health services, Medicare Australia introduced Medicare Benefits Schedule (MBS) items for mental health services under the Better Access Initiative in November 2006. The Initiative allows patients with a mental health condition to receive up to twelve individual mental health services per year, including consultations with eligible psychologists, social workers and occupational therapists. Rebates for these services are available to patients who have been referred by a psychiatrist, paediatrician or via a General Practitioner (GP) Mental Health Care Plan or a Psychiatrist Assessment and Management Plan [6].

According to Medicare data, uptake of MBS mental health (MH) items has been rapid and substantial. From November 2006 to October 2007 the items accounted for 1,209,191 services [7]. Growth was greater within metropolitan locations, compared with rural and remote areas [6] and it was thought that initial beneficiaries were largely those already receiving counselling services [5]. However a survey of psychologists showed that $81 \%$ of clients seen under the $\mathrm{MH}$ items were new to the practice, and $72 \%$ of new clients had not previously seen a psychologist [8]. The survey also reported that $36 \%$ of people seen under the Better Access Initiative were aged 25 years or less, 57\% were between 26 to 65 years, and $7 \%$ were over 65 years [8].

There is otherwise little information about the characteristics of people who use $\mathrm{MH}$ services. Consequently it is not known whether providing subsidised services addresses inequities in service access [5]. The aims of this project were:

1. to describe uptake of $\mathrm{MH}$ items by women participating in the Australian Longitudinal Study on Women's Health (ALSWH) [9], particularly those who reported mental health problems on one or more surveys, and

2. to determine and compare characteristics of women who have and have not used the $\mathrm{MH}$ items, and investigate the impact of the items on the costs of Medicare services.

\section{METHOD}

The study involved analysis of longitudinal data from ALSWH, a national population-based study of the health of cohorts of Australian women born in 1921-26 (older cohort), 1946-51 (mid-age cohort), and 1973-78 (younger cohort). Women were randomly selected from the Medicare database [10] and all cohorts completed the baseline survey in 1996. The first follow-up survey was conducted for the mid-age cohort in 1998, older cohort in 1999, and 
younger cohort in 2000. Subsequent follow up surveys were conducted on a rotational basis every three years. This study includes women who participated in follow-up surveys 4 (S4) in 2005 and 2006 for the older and younger cohorts and survey 5 (S5) in 2007 for the mid-age cohort, who consented to linkage of their ALSWH survey data with Medicare records.

At each survey, women were asked whether a doctor had told them they had any of a list of chronic health conditions including depression and anxiety (and postnatal depression in younger women). Health status was measured by the Short Form Health Survey [11] which includes a Mental Health Index [11, 12] which correlates highly with other measures of depression and anxiety [13], [14, 15].

Survey questions included number of visits to a GP, specialist doctor, optician, dentist, counsellor, or other allied health care provider, admission to hospital in the previous 12 months, and number and type of prescribed medications [16]. Additionally, women were asked about health insurance, smoking, alcohol consumption, weight and height (used to calculate body mass index (BMI)) [17] physical activity [10]. Socio-demographic data on age, marital status, education and country of birth were collected. Urban, inner regional outer regional or remote area of residence was classified using the Accessibility/Remoteness Index of Australia [18].

For consenting women (43\% of S4 respondents in the younger cohort, $64 \%$ of S5 respondents in the mid-age cohort, and $66 \%$ of 54 respondents in the older cohort), survey and MBS data were linked (January 1996-December 2007), including claims under the Better Access Initiative (item numbers $80000-80170$ psychologists and other allied health professionals and 2710 GP Mental Health Plan).

The study was approved by the Human Research Ethics Committee of the University of Newcastle.

\section{STATISTICAL ANALYSIS}

MBS data were examined to identify claims for rebates for MH items from November 2006 to December 2007. Within each cohort, MBS data were used to define users and non-users of MH items and women's self-report of diagnosed mental health problems were used to classify women according to self-report of a mental health condition (depression, anxiety or other mental health condition) on the most recent or any previous survey. Women with $\mathrm{MH}$ item claims were treated as one group in which all were assumed to have a mental health condition (as a condition of referral) regardless of their survey responses. The group of women with no mental health claims was further sub-divided into three groups: women with no reported mental health condition; women who reported a mental health condition on their most recent survey, and women who reported a mental health condition on any but the most recent survey.

Chi-square and t-tests were used to examine the association between factors measured on the surveys across the four groups, and cell contribution to chi-square was used to examine effects within different categories. Generalised Mixture Models were used to compare changes in SF-36 Mental Health Index scores for women in these different groups over time 
(and in relation to the introduction of $\mathrm{MH}$ items), after adjusting for socio-demographic factors including education, smoking, marital status, urban/non-urban area of residence, difficulty managing on income and BMI. Linked data allowed analysis of health service use and costs for each group of women by adding up all costs to government (benefit costs) and all out-of-pocket costs for each year and dividing by the number of women. Costs were adjusted for inflation (2007\$A).

\section{RESULTS}

Data were available for 3,869 women in the younger cohort who completed the most recent survey (S4), 6,690 women in the mid-age cohort (S5), and 4,352 women in the older cohort (S4). From November 2006 to December 2007, 5\% of women in the younger cohort, $2 \%$ of women in the mid-age cohort, and less than $1 \%$ of women in the older cohort had made claims for $\mathrm{MH}$ items. Figure 1 shows that the most common items were for a GP mental health plan, clinical psychologists and other psychologist services.

Among women who reported depression, anxiety or other mental health condition on the most recent survey, $12 \%$ of those in the younger cohort, $10 \%$ of the mid-age cohort, and $1 \%$ of the older cohort had used $\mathrm{MH}$ items (see Table 1).

Since few women in the older cohort used the MH items, data from these women were not analysed further. For women in the younger and mid-age cohorts, four groups were defined according to use of $\mathrm{MH}$ items and self-reported diagnosis of mental health problems:

1) $\mathrm{MH}$ item claims ( regardless of self-reported mental health conditions): $5 \%$ of younger women, $2 \%$ of mid-age women.

2) No MH item claims, but a recent mental health condition: $16 \%$ of younger women, $15 \%$ of mid-age women.

3) No MH item claims, but a past mental health condition: $12 \%$ of younger women, $17 \%$ of mid-age women.

4) No MH item claims and no mental health condition: $67 \%$ of younger women, $65 \%$ of mid-age women.

Group comparisons in Table 2 indicate socio-demographic and health differences between these groups of women. Similar findings were for the mid-age cohort (data not shown). Women in Group 2 were more likely to visit a GP, specialist or hospital doctor and more likely to report taking medications for nerves, depression, or to help them sleep. There were no differences by area of residence, alcohol intake or country of birth.

Figure 2 shows SF-36 Mental Health Index scores for the younger and mid-age cohorts. Lower scores indicate poorer mental health-related quality of life. Mental Health Index scores for women in both cohorts were lowest for women in Groups 1 and 2. Over time, there was an improvement in scores for women in Group 3 (S4 for younger cohort, S5 for mid-age cohort). For women in the mid-age cohort who had used MH items (Group 1) the 
Mental Health Index score dropped significantly from survey 4 in 2004 to survey 5 in 2007, indicating a decline in mental health-related quality of life.

Figures 3 and 4 show the increase in patient (out of pocket) and benefit (government) costs following introduction of the $\mathrm{MH}$ items. Uptake of $\mathrm{MH}$ items was associated with a steep increase in both cost types during 2007 with average yearly increases of $\$ 100-\$ 150$ for the women, and $\$ 600-\$ 800$ for the government.

\section{DISCUSSION}

While earlier reports provided evidence of rapid uptake of $\mathrm{MH}$ items, these findings indicate that the per capita impact of the items is small. A large proportion of women reporting a history of mental health problems had no claims suggesting that issues of access were not being addressed as intended [19]. After analysing data from the 1997 National Survey of Mental Health and Wellbeing, Andrews et al. [20] reported that for every nine people with a mental health disorder, only one had consulted a mental health professional in the previous year. Andrews et al. [20] also reported that women were almost twice as likely to consult a mental health professional as men, and so the impact of the $\mathrm{MH}$ items among men may be expected to be lower than observed for women in this study. Our data show that women who are more socioeconomically disadvantaged are less likely to access these services, despite mental health needs. The data also show a particularly low uptake of the items by the oldest group of women, consistent with other research suggesting under-treatment of mental health problems among older people [21]. On the other hand, among women who did use the services, very few had previously reported seeing a counsellor, psychologist or social worker indicating that new items reached women who were not previously accessing mental health care.

Although it is premature to fully explain the impact of the items on women's mental health, women in the mid-age cohort who used services covered by $\mathrm{MH}$ items had a steep decline in their mental health scores between survey 4 and survey 5 . Women who had worsening mental health were more likely to be referred for services covered by $\mathrm{MH}$ items, although there are insufficient data points to determine the directionality of this effect. Data for women in the younger cohort did not cover the period following the introduction of the $\mathrm{MH}$ items which may partly explain the different patterns observed for these women. Further exploration of these changes will be possible when data on subsequent use of $\mathrm{MH}$ items and further mental health outcomes become available.

The $\mathrm{MH}$ items are associated with increases in costs for women and for governments. It is therefore critical that the impact and equity of impact of these items is assessed further. This imperative exists not only because of costs to government, which have been described as considerable $[7,19]$ but also in view of the added economic stress on individual women and the potential for the Scheme to increase health inequalities. If women who have difficulty managing on income and who have lower educational levels are less able to make use of $\mathrm{MH}$ services despite their mental health needs, then the Scheme does not necessarily address gaps in service provision as intended. 
While our data provide information on characteristics of women using services covered by $\mathrm{MH}$ items, there are some limitations. One limitation is that not all women in ALSWH consented to linkage with MBS data. Comparison between consenters and non-consenters at the time of completing Survey 4 indicates small but statistically significant differences according to area of residence (consenters in the mid-age and older cohorts being more likely to live in inner regional areas and less likely to live in outer regional or remote areas). In all three cohorts, women who gave consent to linkage tended to be better educated and were more likely to be able to manage on their available income which suggests a socioeconomic bias among consenters [22]. However, if more disadvantaged women are less likely to use $\mathrm{MH}$ items in spite of $\mathrm{MH}$ needs, then uptake of the items is likely to be even lower than shown here.

Other limitations include that some women may be accessing focussed psychological services under the Better Outcomes in Mental Health Care (BOiMHC) program which complements the Better Access Scheme and which is outside of the Medicare Benefits Schedule http://www.health.gov.au/internet/main/publishing.nsf/Content/mental-boimhcataps. By 2008 , it was estimated that 153,000 Australians had used these services. While some of this use would be picked up by the women's self-reported visits to counsellors, there may be some under-reporting of these services.

A further limitation is the use of self-reported diagnoses to identify mental health needs among women who have not used the $\mathrm{MH}$ items. This may result in some misclassification of the three groups of non-users and it is likely that differences between the groups will be under-estimated.

Strengths of the study include that the results are based on a national random sample of women rather than a clinical sample, and can therefore be more readily generalised to the wider population; linkage of MBS and ALSWH records means that personal characteristics of women using and not using the $\mathrm{MH}$ items can be assessed, and the use of longitudinal data allows for inclusion of mental health histories in the analyses.

\section{CONCLUSION}

The potential of the Better Access Initiative to meet the mental health needs of large numbers of people should not be under-estimated. However, while there has been rapid uptake of the $\mathrm{MH}$ items, their use by women with mental health needs is proportionally low and there is potential for socioeconomic inequity. In view of the costs both to governments and individuals there is an urgent need to evaluate outcomes of the Initiative in terms of equity and cost effectiveness. 
Table 1: Use of MBS Mental Health items by women with recent and past reports of a mental health condition

\begin{tabular}{|c|c|c|c|}
\hline & $\mathbf{N}$ & Mental Health & No Mental Health \\
\hline \multicolumn{4}{|l|}{ Younger cohort (1973-78) } \\
\hline Report of mental health condition on & 702 & $12 \%$ & $88 \%$ \\
\hline Report of mental health condition in a & 504 & $6 \%$ & $94 \%$ \\
\hline No Report of mental health condition & 2663 & $2 \%$ & $98 \%$ \\
\hline \multicolumn{4}{|l|}{ Mid cohort (1945-51) } \\
\hline Report of mental health condition on & 1130 & $10 \%$ & $90 \%$ \\
\hline Report of mental health condition in a & 1171 & $2 \%$ & $98 \%$ \\
\hline No Report of mental health condition & 4389 & $0.5 \%$ & $99.5 \%$ \\
\hline \multicolumn{4}{|l|}{ Older cohort (1921-26) } \\
\hline Report of mental health condition on & 431 & $1 \%$ & $99 \%$ \\
\hline Report of mental health condition in a & 271 & $1 \%$ & $99 \%$ \\
\hline No Report of mental health condition & 3650 & $0 \%$ & $100 \%$ \\
\hline
\end{tabular}

Notes: Some women did not self-report a mental health condition but had MH claims may have developed a mental health condition after survey 4. 
Table 2: Characteristics of women from 1973-78 cohort according to use of MBS mental health items and reporting of recent or past mental health condition

\begin{tabular}{|c|c|c|c|c|}
\hline & $\begin{array}{l}\text { Group 1: } \\
\text { Any MH } \\
\text { item }\end{array}$ & $\begin{array}{l}\text { Group 2: } \\
\text { No } \mathrm{MH} \text { item but } \\
\text { recent } \mathrm{MH} \\
\text { condition }\end{array}$ & $\begin{array}{c}\text { Group 3: } \\
\text { No MH item but } \\
\text { past MH condition }\end{array}$ & $\begin{array}{l}\text { Group 4: } \\
\text { No MH item } \\
\text { or MH } \\
\text { condition }\end{array}$ \\
\hline \multirow[t]{2}{*}{$\mathrm{N}$} & 168 & 621 & 476 & 2604 \\
\hline & $\%$ & $\%$ & $\%$ & $\%$ \\
\hline $\begin{array}{l}\text { No post school educational } \\
\text { qualifications }\end{array}$ & 13 & $23^{*}$ & 21 & 16 \\
\hline \multicolumn{5}{|l|}{ Marital Status } \\
\hline Married/De facto & 57 & 65 & 73 & 76 \\
\hline Single & $38^{*}$ & 28 & 21 & 22 \\
\hline Sep/Divorced & 6 & $7^{*}$ & 6 & $2^{*}$ \\
\hline Difficult to Manage on Income & 17 & $19 *$ & 15 & 8 \\
\hline BMI Overweight (>30) & 29 & $45^{*}$ & 39 & 37 \\
\hline Current Smoker & 20 & $23^{*}$ & 20 & $13^{*}$ \\
\hline \multicolumn{5}{|l|}{ GP Visits in the past year } \\
\hline At Most 4 & 52 & 50 & 63 & 75 \\
\hline 5-8 times & 36 & 32 & 25 & 19 \\
\hline 9 or More & 12 & $18^{*}$ & 12 & 6 \\
\hline $\begin{array}{l}\text { Visits to specialist doctors (any in } \\
\text { the past year) }\end{array}$ & 60 & $58^{*}$ & 52 & 46 \\
\hline $\begin{array}{l}\text { Visits to hospital doctors (any in } \\
\text { the past year) }\end{array}$ & 24 & $32^{*}$ & 25 & 21 \\
\hline $\begin{array}{l}\text { Private Health Insurance for } \\
\text { Hospital cover }\end{array}$ & 63 & 51 & 58 & 60 \\
\hline $\begin{array}{l}\text { Visits to } \\
\text { Counsellor/Psychologist/ Social } \\
\text { Worker (prior to introduction of } \\
\text { MH items) }\end{array}$ & $7^{*}$ & 42 & $45^{*}$ & 13 \\
\hline \multicolumn{5}{|l|}{$\begin{array}{l}\text { Self-reported Medication use in } \\
\text { past } 4 \text { weeks }\end{array}$} \\
\hline For Nerves & 6 & $13^{*}$ & 3 & 0.4 \\
\hline To help Sleep & 11 & $46^{*}$ & 18 & 26 \\
\hline For Depression & 20 & $37 *$ & 0.9 & $0.1^{*}$ \\
\hline $\begin{array}{l}\text { Provide care or assistance to any } \\
\text { other } \\
\text { person because of long-term } \\
\text { illness, disability or frailty }\end{array}$ & 6 & $10^{*}$ & 5 & 3 \\
\hline
\end{tabular}


Figure 1: Number of women in each ALSWH cohort with claims for MH Items - December 2006 - December 2007 (13 months)

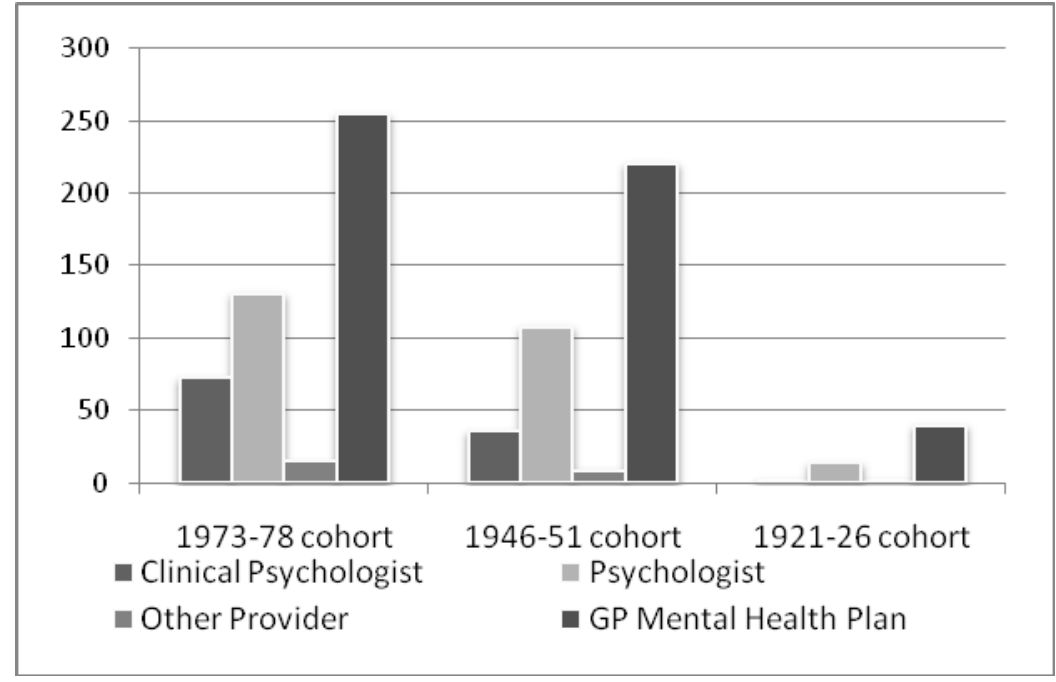

Notes: GP mental health plan (item 2710) clinical psychologist (item 80000, 80001, 80020) and other psychologist services (items $80100,8011080115,80120$ ). Very few women in any cohort used items for services provided by occupational therapists or social workers (items 80135,80160 ). Previously available mental health items, such as the three step mental health process (items $2574,2577,2578$ ), continued to be used at a steady rate by very small numbers of women (fewer than 20 women per item per year - data not shown). 


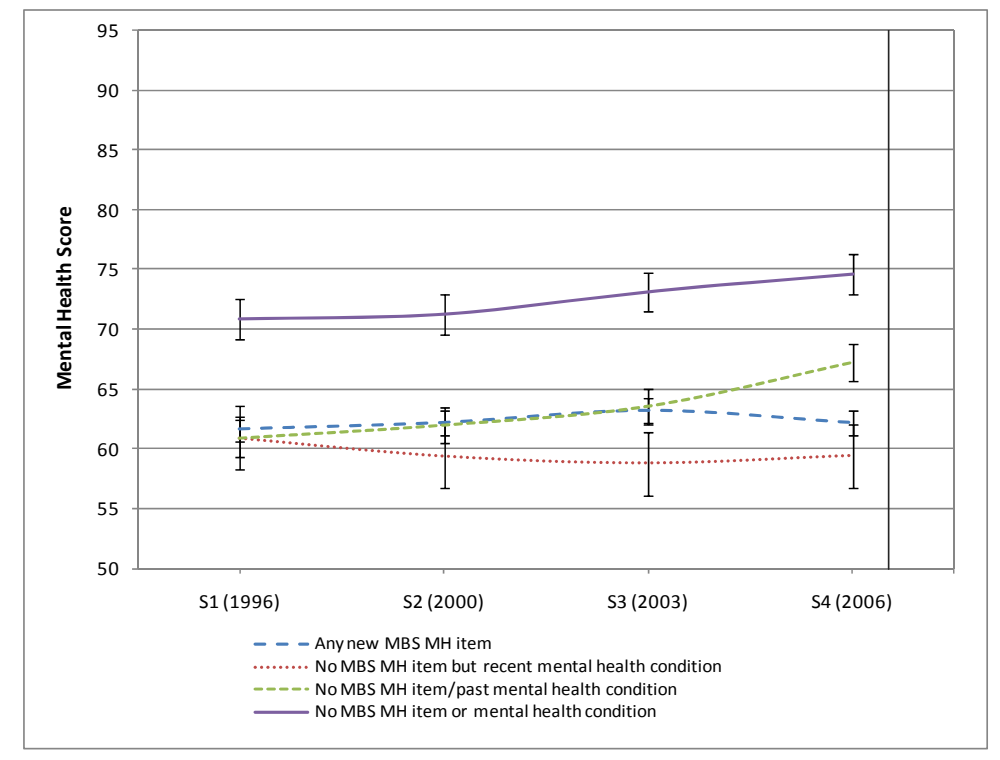

a) $1973-78$ Cohort

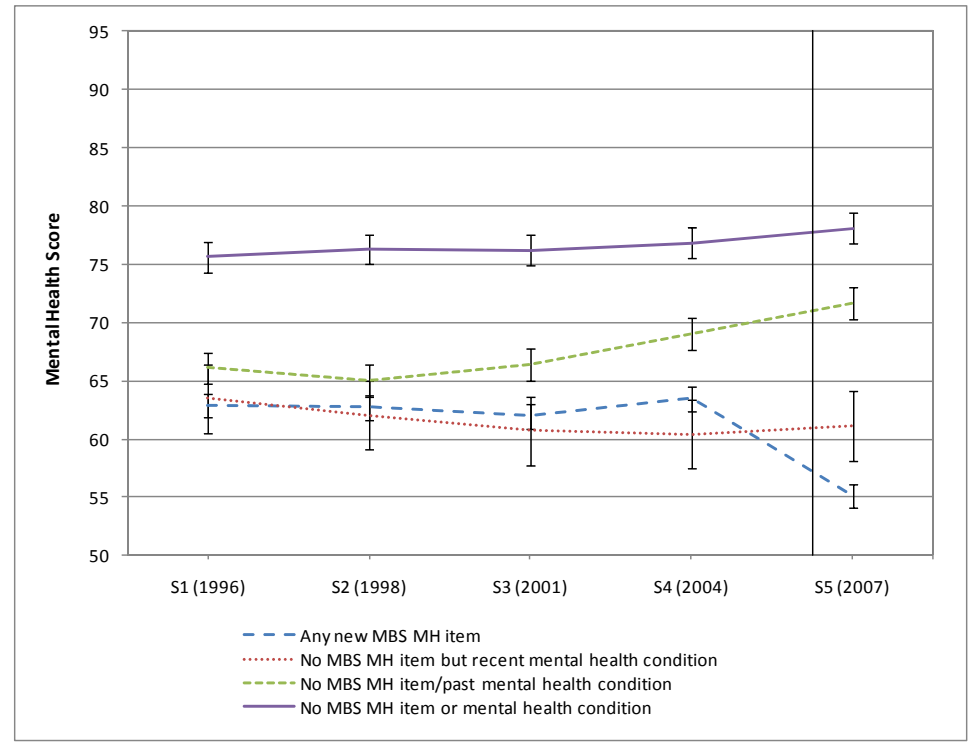

b) 1946-51 Cohort

Figure 2: SF-36 Mental Health Index scores for younger (1973-78) and mid-age (1946-51) ALSWH cohorts according to $\mathrm{MH}$ item claims and recent or past reporting of a $\mathrm{MH}$ condition. Least square means adjusted for time, education, smoking, marital status, urban/non-urban area of residence, difficulty managing on income and BMI. 


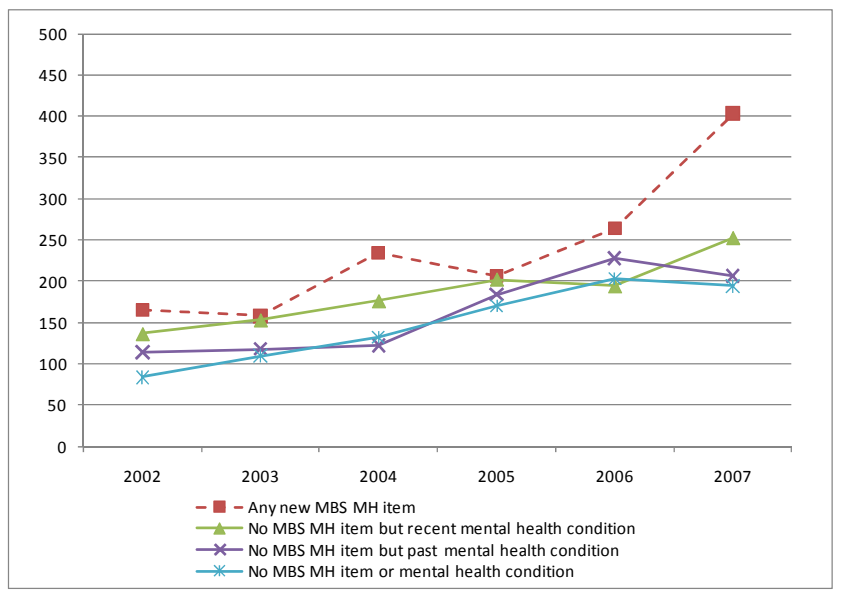

a) $1973-78$ Cohort

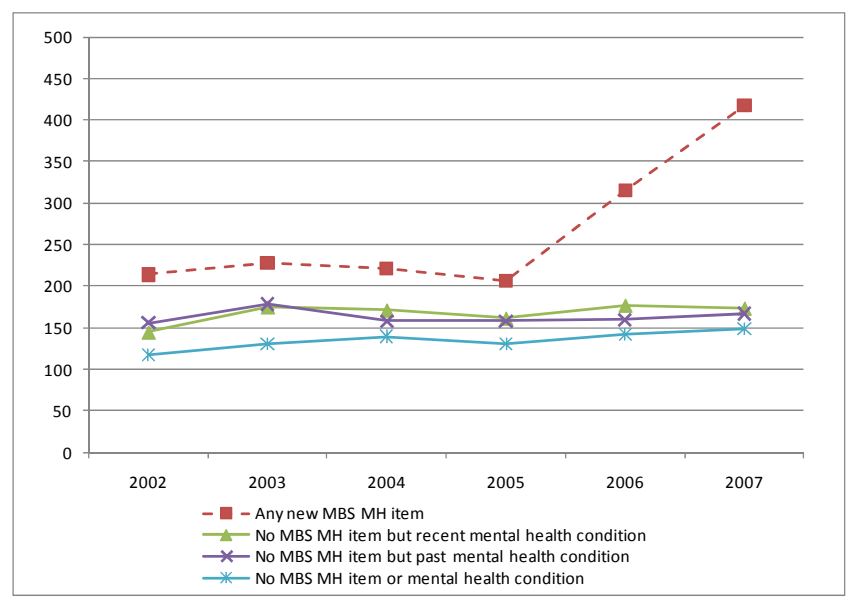

b) $\quad 1946-51$ Cohort

Figure 3: MBS patient costs for women in the younger (1973-78) and mid-age (1946-51) ALSWH cohorts according to $\mathrm{MH}$ item uptake and recent or past $\mathrm{MH}$ condition

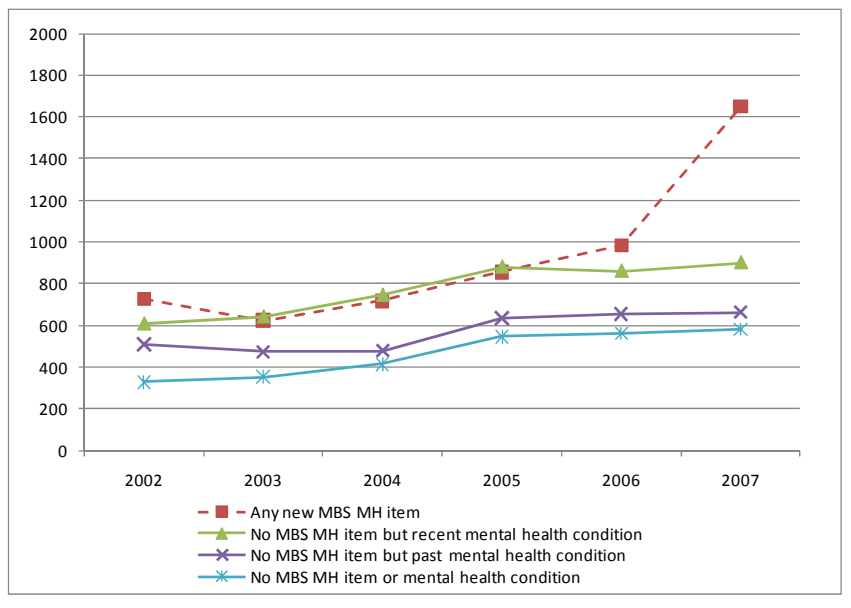

a) $1973-78$ Cohort

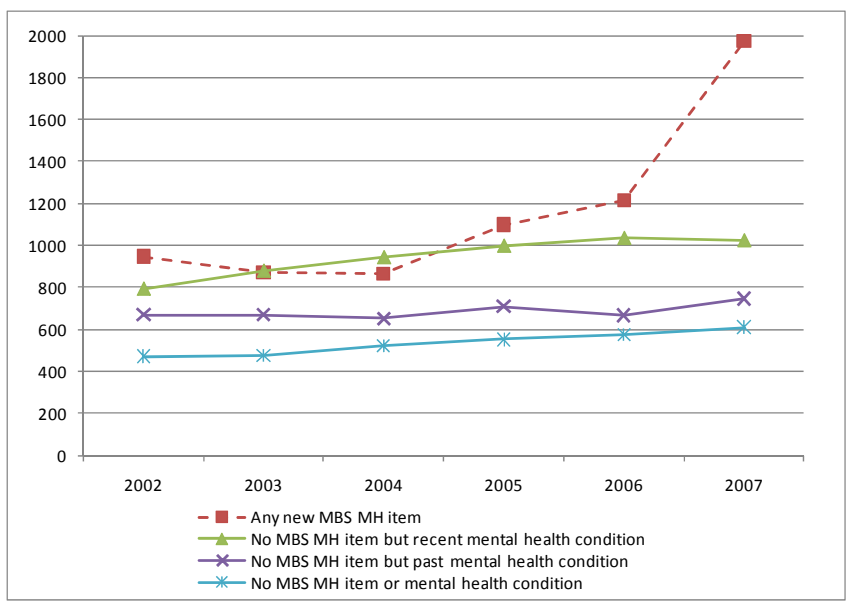

b) 1946-51 Cohort

Figure 4: MBS benefit costs to government for women in the younger (1973-78) and midage (1946-51) ALSWH cohorts according to $\mathrm{MH}$ item uptake and recent or past $\mathrm{MH}$ condition 


\section{REFERENCES:}

[1] Lucht M, Schaub RT, Meyer C, $\underline{\text { Hapke U }}$, Rumpf HJ, Bartels T, et al. Gender differences in unipolar depression: a general population survey of adults between age 18 to 64 of German nationality. Journal of Affective Disorders. 2003;77(3):203-11.

[2] Hyde JS, Mezulis AH, Abramson LY. The ABCs of depression: Integrating affective, biological and cognitive models to explain the emergence of the gender difference in depression. . Psychological Review. 2008;115:291-313.

[3] Abbass A, Hancock J, Henderson J, Kisely S. Short-term psychodynamic psychotherapies for common mental disorders. Cochrane Database of Systematic Reviews. 2006(4):CD004687.

[4] Chisholm D, Sanderson K, Ayuso-Mateos JL, Saxena S, Chisholm D, Sanderson K, et al. Reducing the global burden of depression: population-level analysis of intervention costeffectiveness in 14 world regions. British Journal of Psychiatry. 2004 May;184:393-403.

[5] Hickey I, McGorry P. Increased access to evidence-based primary mental health care: Will the implementation match the rhetoric? Medical Journal of Australia. 2007;178:100-3.

[6] Crosbie D, Rosenberg S. Mental Health and the New Medicare Services: An Analysis of the First Six Months. July 2007 [cited; Available from: http://www.medicare.gov.au

[7] Whiteford H, Doessel D, Sheridan J. Uptake of Medicare Benefits Schedule items by psychologists and other mental health practitioners. Clinical Psychologist. 2008;12(2):50-6.

[8] Australian Psychological Society. "Better Access" to Medicare Mental Health Items and Psychology Providers: Medical Benefits Scheme Report; 2008.

[9] Australian Longitudinal Study on Women's Health (ALSWH). [cited; Available from: <http://www.alswh.org.au/surveys.html >

[10] Brown WJ, Bryson L, Byles JE, Dobson AJ, Lee C, Mishra G, et al. Women's Health Australia: recruitment for a national longitudinal cohort study. Women \& Health. 1998;28(1):23-40.

[11] Ware J, Kosinski M, Keller S. SF-36 ${ }^{\circledR}$ Physical and Mental Health Summary Scales: A User's Manual Boston, MA: The Health Institute 1994.

[12] McCallum J, Shadbolt B, Wang D. Self-rated health and survival: a 7-year follow-up study of Australian elderly. American Journal of Public Health. 1994 Jul;84(7):1100-5.

[13] Goldberg D, Bridges K, Duncan-Jones P, Grayson D. Detecting anxiety and depression in general medical settings. BMJ. 1988 Oct 8;297(6653):897-9. 
[14] Andresen EM, Malmgren JA, Carter WB, Patrick DL. Screening for depression in well older adults: evaluation of a short form of the CES-D (Center for Epidemiologic Studies Depression Scale). American Journal of Preventive Medicine. 1994 Mar-Apr;10(2):77-84.

[15] Australian Longitudinal Study on Women's Health (ALSWH). 10 June 2001 [cited; Available from: http://www.alswh.org.au/Reports/Technical/Report\%2016\%20ALSWH.pdf

[16] Young AF, Dobson AJ, Byles JE. Access and equity in the provision of general practitioner services for women in Australia. Australian \& New Zealand Journal of Public Health. 2000 Oct;24(5):474-80.

[17] World Health Organization Consultation on Obesity. Obesity: preventing and managing the global epidemic: report of a WHO consultation. Geneva, Switzerland; 1999.

[18] Department of Health and Aged Care (GISCA). Measuring remoteness: accessibility/remoteness index of Australia (ARIA). In: (GISCA) DoHaAC, ed. Canberra 2001.

[19] Carey T, Rickwood D, Baker K. What does \$UD27,650,523.80 worth of evidence look like? Clinical Psychologist. 2009;13(1):10-6.

[20] Andrews G, Issakidis C, Carter G. Shortfall in mental health service utilisation. British Journal of Psychiatry. 2001 Nov;179:417-25.

[21] Zhang Y, Chow V, Vitry Al, Ryan P, Roughead EE, Caughey GE, et al. Antidepressant use and depressive symptomatology among older people from the Australian Longitudinal Study of Ageing. International Psychogeriatrics. 2010 May;22(3):437-44.

[22] Byles J, Loxton D, Berecki J, al. e. Use and costs of medications and other health care resources: Findings from the Australian Longitudinal Study on Women's Health. Report to the Department of Health and Ageing, June 2008.; 2008. 